\title{
Article \\ The Effect of Voltage Pulse Shape on the Discharge Characteristics in the Packed Bed Reactor under Air and Nitrogen
}

\author{
Yao Li ${ }^{1}$, Liang Qin ${ }^{1}$, Dezheng Yang ${ }^{1,2, *}$, Li Zhang ${ }^{3}$ and Wenchun Wang ${ }^{1}$ \\ 1 Key Laboratory of Materials Modification by Laser, Ion, and Electron Beams, Dalian University of Technology, \\ Ministry of Education, Dalian 116024, China; liyaoythy@mail.dlut.edu.cn (Y.L.); \\ qinliang@mail.dlut.edu.cn (L.Q.); wangwenc@dlut.edu.cn (W.W.) \\ 2 School of Science, Shihezi University, Shihezi 832003, China \\ 3 College of Electrical Engineering and Control Science, Nanjing Tech University, Nanjing 211816, China; \\ zhangxxxli@163.com \\ * Correspondence: yangdz@dlut.edu.cn
}

Citation: Li, Y.; Qin, L.; Yang, D.; Zhang, L.; Wang, W. The Effect of Voltage Pulse Shape on the Discharge Characteristics in the Packed Bed Reactor under Air and Nitrogen. Appl. Sci. 2022, 12, 2215. https:// doi.org/10.3390/app12042215

Received: 10 December 2021

Accepted: 29 January 2022

Published: 20 February 2022

Publisher's Note: MDPI stays neutral with regard to jurisdictional claims in published maps and institutional affiliations.

Copyright: (C) 2022 by the authors. Licensee MDPI, Basel, Switzerland. This article is an open access article distributed under the terms and conditions of the Creative Commons Attribution (CC BY) license (https:// creativecommons.org/licenses/by/ $4.0 /)$.

\begin{abstract}
In this paper, the packed bed dielectric barrier discharge (DBD) with needle-plate electrode configuration is presented to study the effects of electrical parameters, such as pulse duration and pulse rising and falling time, on discharge characteristics under air and nitrogen. The waveforms of the voltage and the discharge current, discharge evolution images, and the emission spectral of $\mathrm{N}_{2}\left(\mathrm{C}^{3} \Pi_{\mathrm{u}} \rightarrow \mathrm{B}^{3} \Pi_{\mathrm{g}}\right)$ and $\mathrm{N}_{2}{ }^{+}\left(\mathrm{B}^{2} \Sigma_{\mathrm{u}}{ }^{+} \rightarrow \mathrm{X}^{2} \Sigma_{\mathrm{g}}{ }^{+}\right)$are collected to investigate the discharge current, as well as the spatial distribution of the discharge modes and the reactive species in the packed bed reactor specifically. It is found that the pulse duration and pulse rising and falling time can regulate the discharge current. Firstly, increasing the pulse duration and the pulse rising and falling time can both increase the discharge duration. Secondly, the peak value of the discharge current has an obvious increasing trend with the pulse duration. Finally, the discharge start time can be delayed by increasing the pulse rising and falling time. A bright discharge channel is distributed at the top of the reactor, while the discharge is diffused at the bottom of the reactor. The generation of $\mathrm{N}_{2}^{+}\left(\mathrm{B}^{2} \Sigma_{\mathrm{u}}{ }^{+}\right)$ tends to depend on the existence of the streamer channel, and $N_{2}\left(C^{3} \Pi_{u}\right)$ can be generated in the entire discharge area. In addition, the discharge operated in pure nitrogen can reach higher current values, a stronger discharge intensity, and longer existence time for the reactive species than in the air.
\end{abstract}

Keywords: packed bed dielectric barrier discharge; voltage pulse shape; gas composition; optical emission spectrum; discharge images

\section{Introduction}

The dielectric barrier discharge (DBD), which is formed by applying an alternating high voltage across two electrodes between which at least one dielectric appears, is a common way to generate non-thermal plasma [1,2]. As one form of DBD [3], the packed bed reactor excited by nanosecond pulse power is significant in the field of research and application. The rich variety of reactive species [4], the high electric field [5] and the ability of accommodating different dielectric materials [6] are the major characteristics of the packed bed reactor. Furthermore, better combination with the catalyst can change the discharge modes and generate new reactive species in the packed bed reactor (PBR) [7]. Moreover, the synergistic effects between the plasma and catalysis, which can improve the energy efficiency and the yield, make the PBR become the favorite discharge structure to generate non thermal plasma and be widely applied in the field of nitrogen fixation [8,9], volatile organic compound (VOCs) and toluene degradation [10-12], ozone generation [13,14], and $\mathrm{CO}_{2}$ conversion [15], etc.

In the field of environment and energy, such as nitrogen fixation and methane dry reforming, increasing the yield while reducing the energy consumption is always the 
goal, and the optimization of plasma sources is one of the important ways to achieve this. Compared with the traditional DC and AC discharge, the nanosecond pulse has the short pulse duration, the electrons can be accelerated plenty in their free range to obtain energy, and the gas heating can be prevented [16]. Moreover, the uniformity of the discharge can be optimized well by applying the nanosecond pulsed power [17]. In general, the nanosecond pulsed power has a higher energy efficiency and can prevent the glow-to-arc transition $[18,19]$. Thus, it has been the preferred choice for us to initiate packed bed DBD, and it needs to be researched and applied. At the same time, the parameters of the voltage pulse and the corresponding characteristics of the discharge also need to be adjusted and investigated, respectively, to optimize the discharge in applications.

Previous studies have found that the parameters of voltage pulse, such as pulse peak voltage, pulse repetition rate, pulse rising and falling time, pulse duration, and the electrode shape, have significant effects on the discharge characteristics. Shao et al. [20] found that the gap length, pulse repetition rate, and the variety of the dielectrics can affect the transition between the diffuse "glow-like" discharge mode and filamentary mode. Yang and Zhang et al. [21,22] investigated the effects of the pulse peak voltage, pulse repetition rate, and gas composition to DBD and found that the generation of reactive species can be promoted by adjusting these three parameters, and the delay of the photocurrent peak decreases with the increase in the pulse peak voltage. Li et al. [23] studied the characteristics of DBD with a wedge-shaped electrode. Ono et al. [24] investigated the connection between pulse duration and discharge phases, which have direct effects on the production of reactive species. Furthermore, reactive species, which play an important role in applications, have strong connections with discharge modes in a packed bed reactor. In our previous studies, the discharge evolution process and the corresponding production and quenching processes of reactive species have been studied carefully [25]. Furthermore, the gas composition is also an important influencing factor for packed bed DBD. According to studies, the homogenous discharge, which is beneficial to the material modification, has been obtained in helium, neon, and nitrogen [26]. However, considering the higher cost of the helium and neon, and the larger consumption of the gas during application, nitrogen-plasma is more preferable for researchers to study and apply.

In this work, a simple model of a packed bed DBD is designed to further explore the influences of the parameters of voltage pulse and gas composition on the packed bed DBD. The aim is to investigate the roles played by the pulse duration and pulse rising, and falling time to discharge characteristics and reactive species under air and nitrogen. The spatial distributions of the reactive species and the discharge are discussed by collecting the emission spectrum of reactive species and the intensified charge coupled device (ICCD) images of the discharge.

\section{Experimental Setup}

The experimental setup used in this paper is shown in Figure 1. The experiments are operated under pure nitrogen and air, which is mixed using nitrogen and oxygen with a ratio of $8: 2$ by adjusting the mass flow controller (MFC; S48-300, HoribaStec, Wuxi, China), and the purity of nitrogen and oxygen are both higher than $99.999 \%$. Moreover, the total gas flow rate is $200 \mathrm{~mL} / \mathrm{min}$ during the experiment. The current probe (Tektronix TCP312, $100 \mathrm{MHz}$, Shanghai, China), the high voltage probe (Tektronix P6015A, 1000×, $3.0 \mathrm{pF}$, $100 \mathrm{M} \Omega$, Shanghai, China), and the oscilloscope (Tektronix, MDO3034, $350 \mathrm{MHz}$, Shanghai, China) constitute the electrical diagnosis system, which is used to record the voltage and current waveforms of the discharge. Moreover, the discharge modes and the optical emission spectrum from the generated reactive species are captured by the ICCD camera (Andor New iStar DH334T, Belfast, UK), optical fiber and monochromator (Andor SR-750i, grating groove 2400 lines $/ \mathrm{mm}$, blazed wavelength $300 \mathrm{~nm}$, Belfast, UK), respectively, and display on the computer finally. These four devices compose the optical diagnosis system. The discharge reactor, which includes the high voltage electrode, the ground electrode, the dielectric plate, the dielectric materials, and the closed chamber, is driven by the 
nanosecond pulsed power (HVP-20P, Xi'an Smart Maple Electronic Technology Co. Ltd., Xi an, China). The discharge characteristics, such as the rising and falling time of the voltage pulse, pulse duration, pulse peak voltage, and the pulse repetition rate, can be self-adjusted. Furthermore, the ICCD camera and nanosecond pulsed power can be triggered by a digital delay generator (DG 645, Stanford Research Systems, Sunnyvale, CA, USA) to obtain the time resolved information of the discharge and the reactive species. Figure $1 \mathrm{~b}$ shows the enlarged view of the electrode structure. The shape of the high voltage electrode is a hollow needle tube ( 304 white steel), and the inner and outer diameters are $0.90 \mathrm{~mm}$ and $1.26 \mathrm{~mm}$, respectively. The dielectric materials, with a diameter of $2 \mathrm{~mm}$, are alumina cylinders, which are always used as the support of the catalyst. To simplify the traditional packed bed reactor, three cylinders are placed (as Figure 1b shows), and the needle electrode is placed directly above the upper cylinder. The dielectric plate, with a thickness of $1 \mathrm{~mm}$, is placed on the ground electrode ( 304 white steel) and it is made of alumina. The $2 \mathrm{~mm}$-thick reactor wall is made of quartz to observe the discharge and to collect the optical emission spectrum conveniently. In addition, the "top" and "bottom", marked in Figure 1b, are two spatial positions used to study the distributions of the discharge and reactive species.

(a)
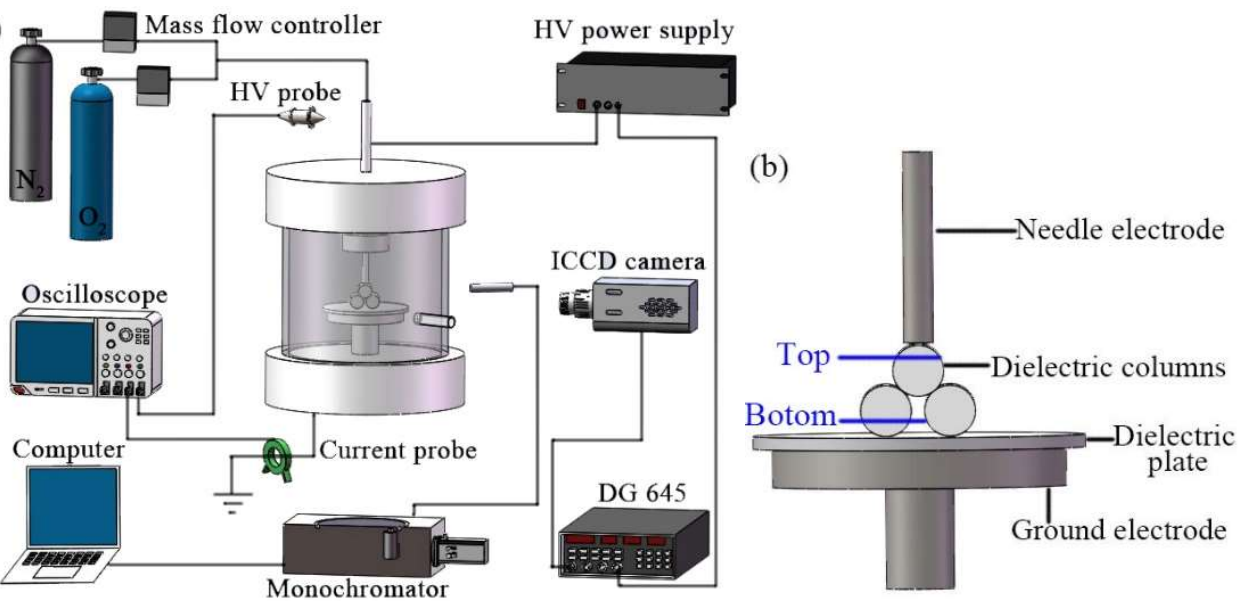

Figure 1. (a) The experiment setup and (b) magnified view of the electrode structure.

\section{Results and Discussion}

\subsection{The Effects of Pulse Duration on Electrical Characteristics}

Figure 2 shows the typical waveforms of the applied voltages and the corresponding discharge currents in air. The pulse peak voltage and pulse repetition rate are set as $15 \mathrm{kV}$ and $1 \mathrm{kHz}$, respectively, and the pulse durations of the voltage pulse in Figure 2 are set as $0 \mathrm{~ns}, 20 \mathrm{~ns}, 60 \mathrm{~ns}$, and $100 \mathrm{~ns}$, respectively. It is found that there are three obvious discharge current peaks during one voltage pulse. The first discharge current peak occurs during the rising time of the voltage pulse and, correspondingly, the second discharge current peak occurs during the falling time of the voltage pulse. We named these two discharge current peaks as the first peak (FP) and the second peak (SP) of the discharge current, respectively. As the pulse peak voltage during the pulse duration is not ideally maintained as a constant, there is a voltage difference during the pulse duration. Thus, the third discharge current peak appears during the pulse duration. Moreover, the discharge duration becomes longer with the increase of the pulse duration, and the reason will be explained below. It should be pointed out that the shape of the voltage and current waveforms in air are the same as those in pure nitrogen. In Figure 3, the peak values of the FP and SP of the discharge current under air and pure nitrogen are calculated. It shows that the four curves in Figure 3 all present an increasing trend with the increase of pulse duration, and in the studies of Pan et al. [27] and Takao et al. [28], they also found that the discharge current density and the electron density increase drastically with the increase of the pulse duration. The reason is that the discharge can be maintained during the pulse duration due to the crucial 
role played by the penning ionization between the metastable state molecules [27]. Hence, the discharge current and the discharge duration get longer when increasing the pulse duration. Additionally, the current value of the discharge operated in pure nitrogen is higher than that in air; this is due to the electron attachment by $\mathrm{O}_{2}[29,30]$, and the main electron attachment reactions [30] are listed as follows ( $\mathrm{M}$ stands for the third body in the three-body attachment reactions, it can be $\mathrm{N}_{2}$ or $\mathrm{O}_{2}$ ).

$$
\begin{gathered}
\mathrm{e}^{-}+\mathrm{O}_{2} \rightarrow \mathrm{O}^{-}+\mathrm{O} \\
\mathrm{e}^{-}+\mathrm{O}_{2}+\mathrm{M} \rightarrow \mathrm{O}_{2}^{-}+\mathrm{M}
\end{gathered}
$$
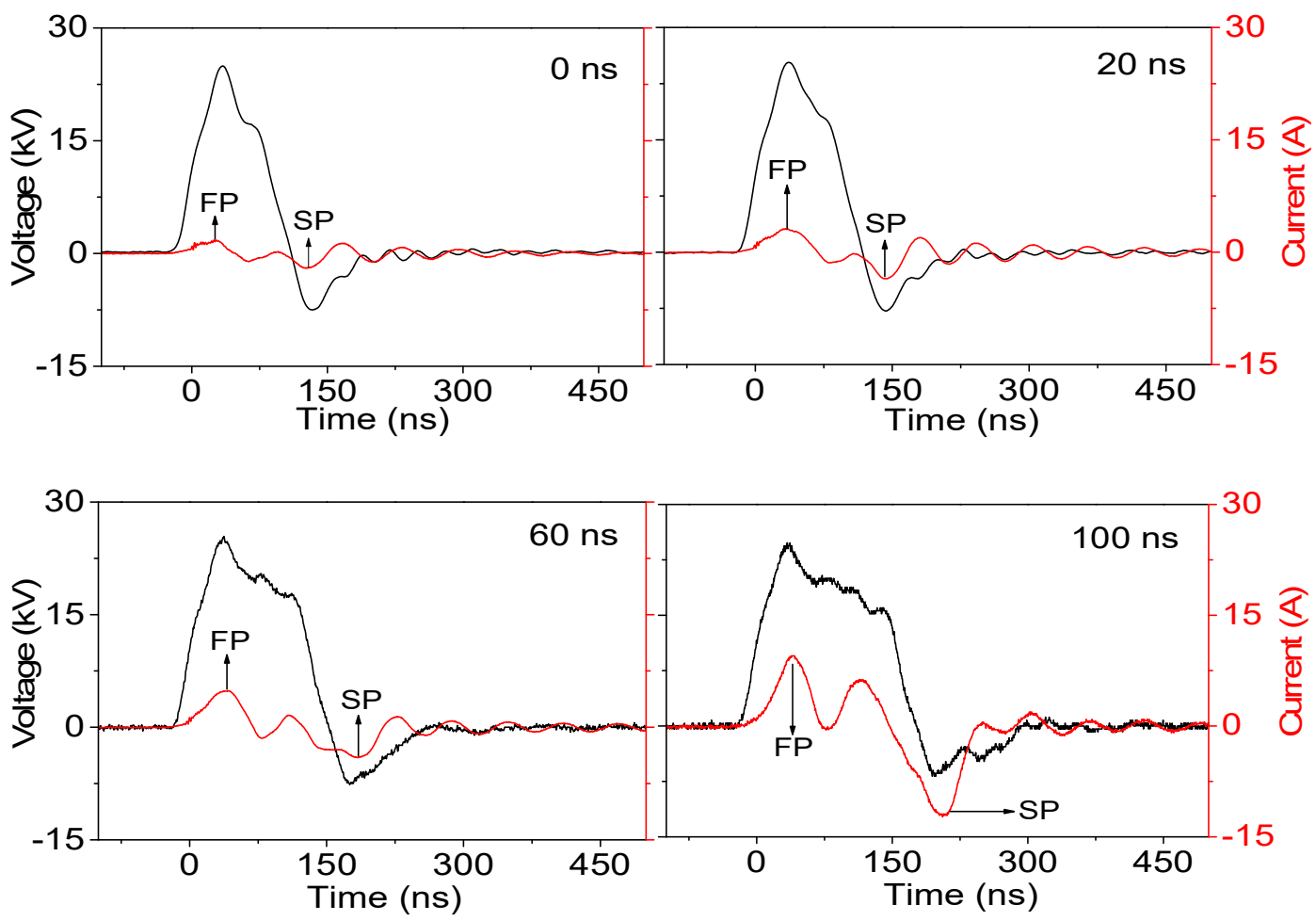

Figure 2. Waveforms of the applied voltages and discharge currents under different pulse durations in air.

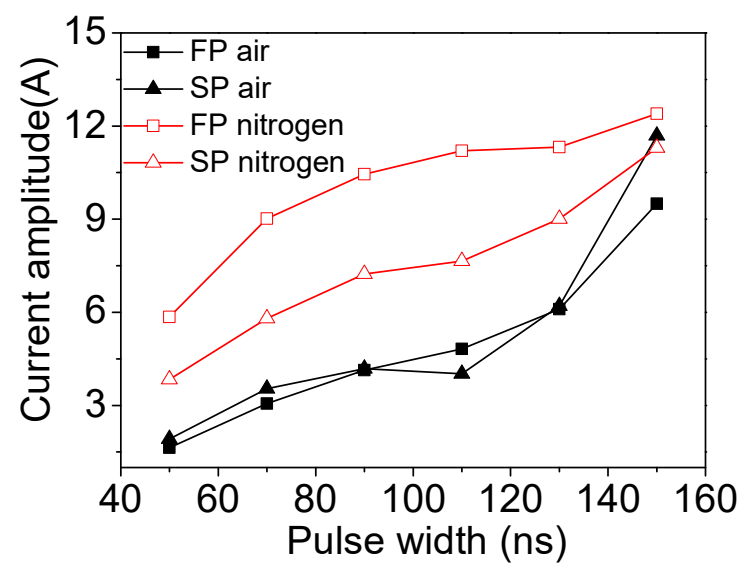

Figure 3. Effects of pulse duration on the peak values of the first and second discharge currents under air and nitrogen. 


\subsection{The Effects of Pulse Rising and Falling Time on Electrical Characteristics}

To study the effects of the rising and falling time of the voltage pulse on discharge, Figure 4 shows the corresponding waveforms of the applied voltages and discharge currents in air with the rising and falling time of the voltage pulse changed synchronously from $50 \mathrm{~ns}$ to $200 \mathrm{~ns}$. The pulse peak voltage, the pulse repetition rate, and the pulse duration are set as $15 \mathrm{kV}, 1 \mathrm{kHz}$, and $40 \mathrm{~ns}$, respectively. As the rising and falling time of the voltage pulse increases, the third discharge current peak during the pulse duration is not obvious, and only the FP and SP of the discharge current can be observed during the rising and falling time of the voltage pulse, respectively. Because the pulse duration is about $40 \mathrm{~ns}$, which is significantly shorter than the rising and falling time of the voltage pulse, the voltage difference during the pulse duration can be ignored. In addition, the start time of FP of the discharge current during the rising time of the voltage pulse is delayed with the increase of the pulse rising time. The reason is that the voltage change rate $(\mathrm{dv} / \mathrm{dt})$ decreases with increasing the pulse rising time, and a longer time is needed for increasing the applied voltage to the breakdown voltage, which is not changed under the same electrode structure. Furthermore, the current duration becomes longer with the increase of the pulse rising and falling time, which coincides with the conclusion obtained by Zhang et al. [31].
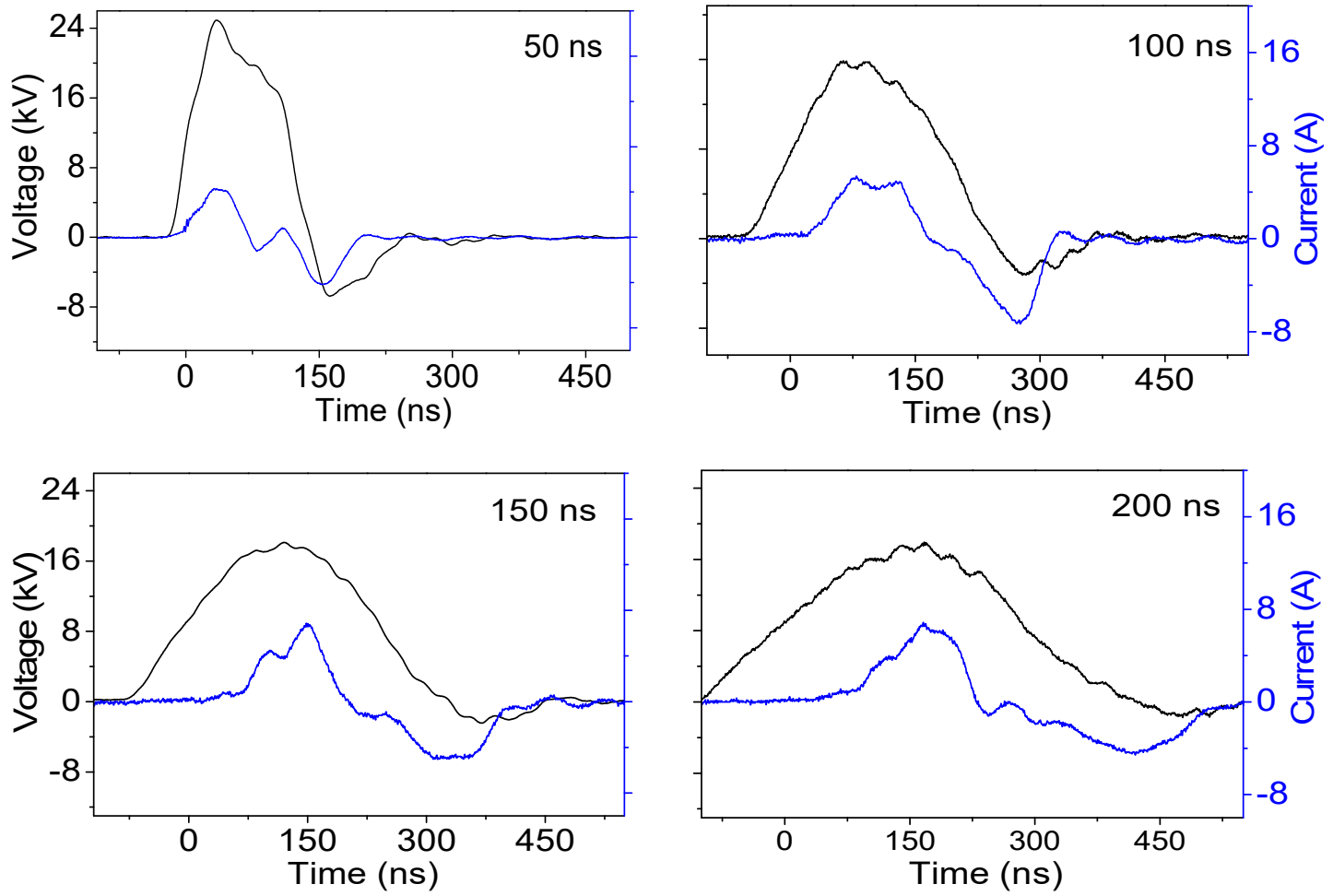

Figure 4. Waveforms of the applied voltages and discharge currents under different pulse rising and falling times.

Figure 5 shows the peak values of the FP and SP of the discharge currents in air and pure nitrogen. The peak values of the FP of the discharge current are almost unchanged in pure nitrogen, but an upward trend in the air with increasing the pulse rising and falling time is seen. The peak values of SP of the discharge current both increase first and then decrease with increasing the pulse rising and falling time, and the maximum is obtained as the pulse rising and falling time are set to $100 \mathrm{~ns}$. To observe the effects of the pulse rising and falling time on the discharge current clearly, the sum of the FP and SP of the discharge current is calculated in Figure 6. It can be found that the discharge currents in pure nitrogen are also higher than those in air, and the reason is explained before. In fact, the characteristics of the discharge currents can reflect the state of the discharge. When the pulse rising and falling time is set as $50 \mathrm{~ns}$, the discharge is weak and the discharge duration 
is short. With increasing the pulse rising and falling time from $100 \mathrm{~ns}$, the discharge current decreases with the pulse rising and falling time. Because the opposite electric field induced by the charges accumulated on the dielectric materials becomes larger with the increase of the pulse rising and falling time, and the gas voltage decreases when the breakdown happens; thus, the discharge current decreases [32].

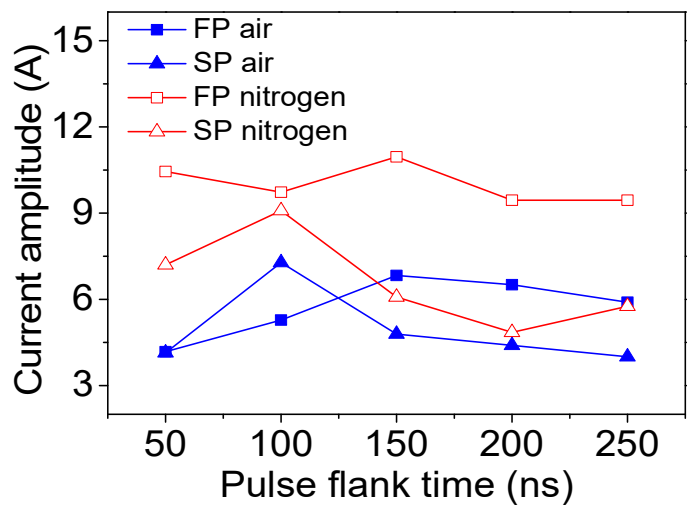

Figure 5. Effects of pulse rising and falling time on the peak values of the first and second discharge currents under air and nitrogen.

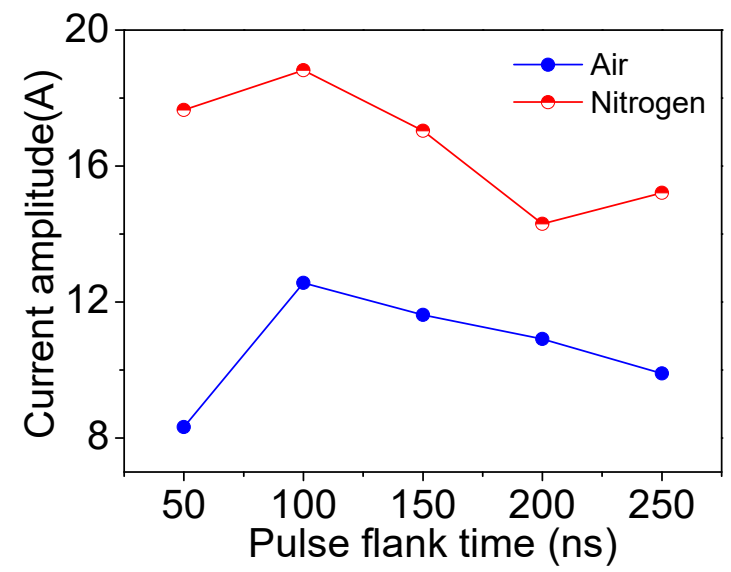

Figure 6. Effects of the pulse rising and falling time on the sum of the peak values of the first and second discharge currents under air and nitrogen.

\subsection{The Discharge Modes in the Reactor}

Figure 7 shows the discharge propagation processes in pure nitrogen and air, and the pulse peak voltage, pulse repetition rate, pulse rising and falling time, and the pulse duration are set as $15 \mathrm{kV}, 1 \mathrm{kHz}, 50 \mathrm{~ns}$, and $80 \mathrm{~ns}$, respectively. It shows that the discharge initiates near the needle electrode and then propagates along the upper cylinder as a streamer (18-43 ns). At $28 \mathrm{~ns}$, the local discharge can be observed at the contact points. Because the opposite charges are much easier to accumulate at the contact points, the electric field can be enhanced and the local discharge can be initiated there [33]. Then, the streamer and the local discharge begin to spread along the wall of the dielectric materials and the lower dielectric plate, respectively. The final discharge morphologies after propagating are shown at $63 \mathrm{~ns}$ in Figure 7a,b. It is clear that there is a bright discharge channel on the top of the reactor, which is significantly different from the diffuse discharge on the bottom. The dynamic evolution processes of the discharge in air are the same as those in pure nitrogen. However, at $63 \mathrm{~ns}$ in Figure 7b, the discharge intensity is weaker and the area of the diffuse discharge is smaller compared with those at $63 \mathrm{~ns}$ in Figure 7a. During the discharge duration when the smallest current peak (the third discharge current peak) appears, the discharge is very weak. Figure $8 \mathrm{a}, \mathrm{b}$ shows the discharge morphology during the falling 
time of the voltage pulse in pure nitrogen and air, respectively. During the pulse falling time, the discharge channel on top of the reactor becomes weaker and the speed of the discharge propagating along the surface of the cylinders is faster than that during the rising time of the pulse. Figure $9 \mathrm{~b}$ is obtained by putting a filter (center wavelength $404.7 \mathrm{~nm}$, half width $10 \mathrm{~nm}$ ) in front of the ICCD camera, and only the light emission from the transition of the second positive system (SPS) of nitrogen molecular $\left(N_{2}\right) N_{2}\left(C^{3} \Pi_{u} \rightarrow B^{3} \Pi_{g}\right)$ can be captured by the ICCD camera. Figure $9 \mathrm{a}$ is the same as the discharge image at $63 \mathrm{~ns}$ in Figure 7a. In addition, the parameters of the voltage pulse in Figure $9 a, b$ are the same. From Figure 9, it is clear that the light emission from the SPS of $\mathrm{N}_{2}$ in pure nitrogen is the main composition of the total light from the discharge. In addition, the same conclusion can also be obtained under air condition [34].
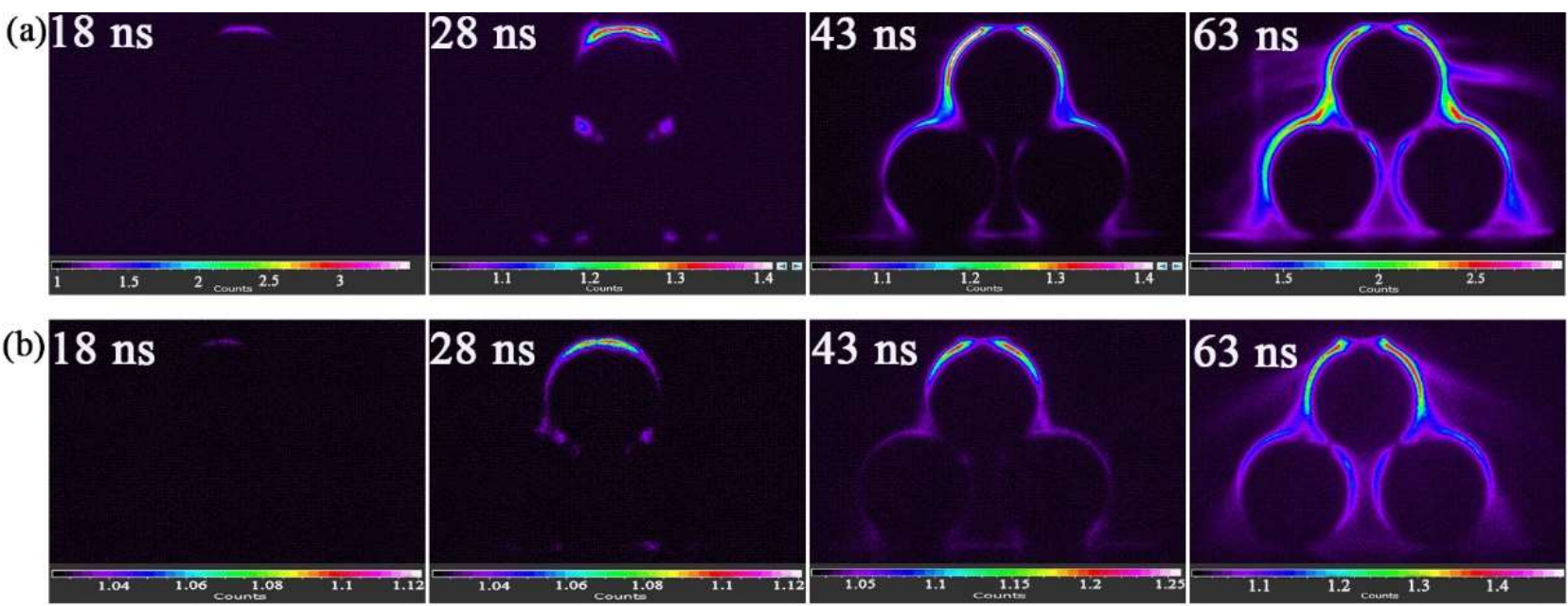

Figure 7. ICCD images of the discharge evolution processes during the rising time of the voltage pulse in (a) pure nitrogen and (b) air.
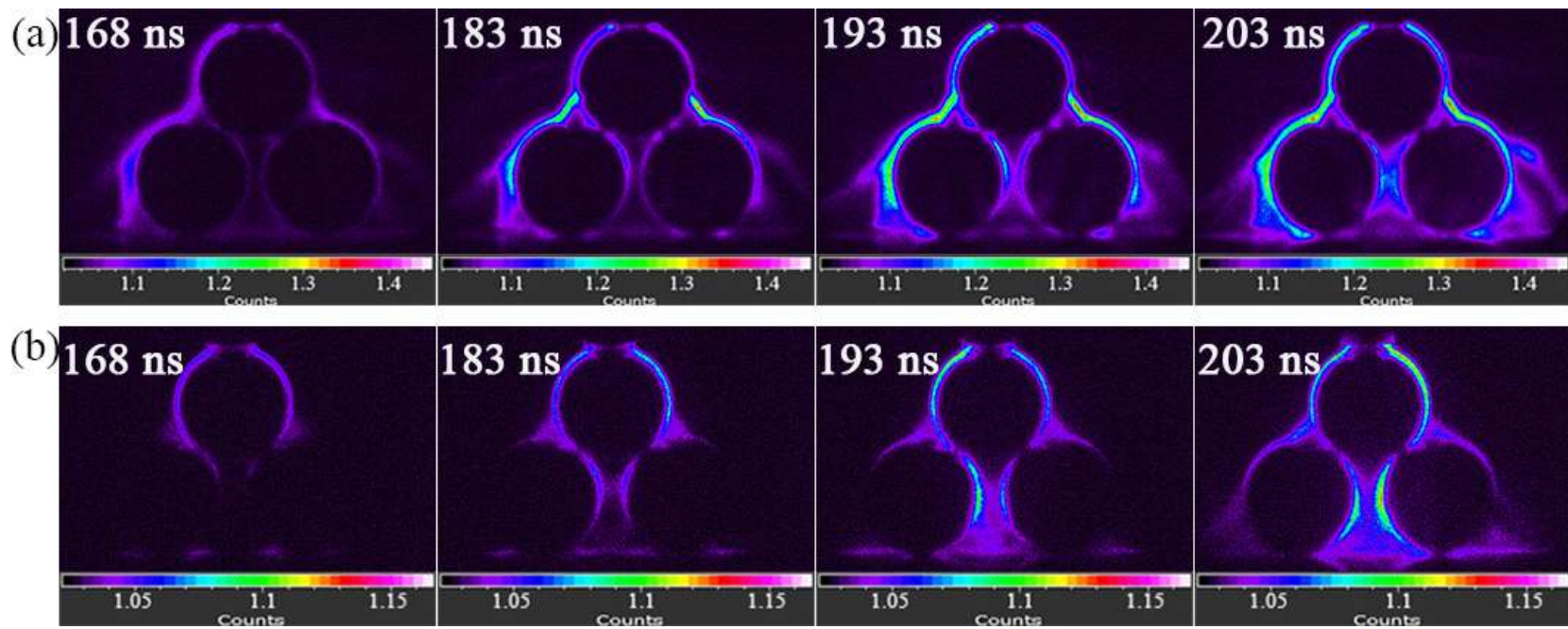

Figure 8. ICCD images of the discharge evolution processes during the falling time of the voltage pulse in (a) pure nitrogen and (b) air. 


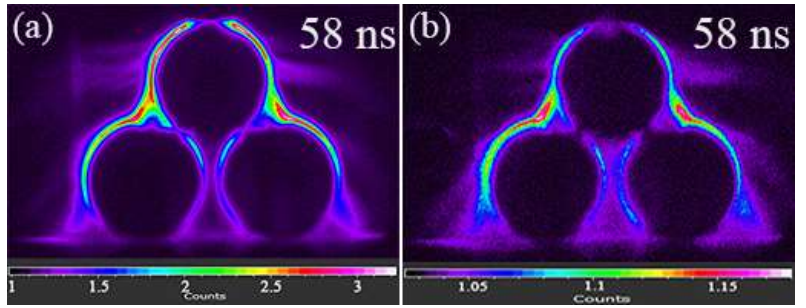

Figure 9. ICCD images of the final discharge morphology during the pulse rising time in nitrogen (a) without a filter and (b) with a filter.

\subsection{The Effects of Pulse Duration on Reactive Species}

The SPS of the nitrogen molecule and the first negative system (FNS) of the nitrogen molecular ion $\left(\mathrm{N}_{2}{ }^{+}\right) \mathrm{N}_{2}{ }^{+}\left(\mathrm{B}^{2} \Sigma_{\mathrm{u}}{ }^{+} \rightarrow \mathrm{X}^{2} \Sigma_{\mathrm{g}}{ }^{+}\right)$are collected to investigate the effects of pulse duration and gas composition on $\mathrm{N}_{2}{ }^{+}\left(\mathrm{B}^{2} \Sigma_{\mathrm{u}}{ }^{+}\right)$and $\mathrm{N}_{2}\left(\mathrm{C}^{3} \Pi_{\mathrm{u}}\right)$ in different positions of the packed bed reactor, and the results are shown in Figures 10 and 11, respectively. The spectra at $337 \mathrm{~nm}$ and $391.4 \mathrm{~nm}$ are chosen to represent the SPS of $\mathrm{N}_{2}$ and FNS of $\mathrm{N}_{2}{ }^{+}$, respectively. In Figure 10, the increase rate of the emission intensity of FNS of $\mathrm{N}_{2}{ }^{+}$at the bottom of the reactor is smaller than that at the top. However, the increase rates of the SPS of $\mathrm{N}_{2}$ at the top and bottom of the reactor does not have obvious differences in Figure 11. The reason is that the production of $\mathrm{N}_{2}{ }^{+}\left(\mathrm{B}^{2} \Sigma_{\mathrm{u}}{ }^{+}\right)$depends on the existence of a streamer channel [35], and there are more streamer channels on the top of the reactor than those on the bottom, which can be seen in Figure 7. Hence, the increase rates of the emission intensity of FNS of $\mathrm{N}_{2}{ }^{+}$are different in the top and bottom of the reactor. As for $\mathrm{N}_{2}\left(\mathrm{C}^{3} \Pi_{\mathrm{u}}\right)$, the excitation potential of $\mathrm{N}_{2}\left(\mathrm{C}^{3} \Pi_{\mathrm{u}}\right)$ is about $11 \mathrm{eV}$ [36], which is much smaller than that of $\mathrm{N}_{2}{ }^{+}\left(\mathrm{B}^{2} \Sigma_{\mathrm{u}}{ }^{+}\right)$. This means that the production of $\mathrm{N}_{2}\left(\mathrm{C}^{3} \Pi_{\mathrm{u}}\right)$ is not dependent on the high energy electrons produced in the streamer channel, and the discharges at the top and the bottom of the reactor can both play roles in generating $\mathrm{N}_{2}\left(\mathrm{C}^{3} \Pi_{\mathrm{u}}\right)$. As a result, there is no obvious difference in increase rate at the top and bottom of Figure 11. For the same reason, the emission intensity of the SPS of $\mathrm{N}_{2}$ is stronger than the emission intensity of FNS of $\mathrm{N}_{2}{ }^{+}$. The intensities of FNS of $\mathrm{N}_{2}{ }^{+}$in Figure 10 and the SPS of nitrogen molecule in Figure 11 both increase with the increase in pulse duration. This is because the discharge currents increase with the pulse duration (shown in Figure 3), which leads to an increase of the electron density, and more $\mathrm{N}_{2}{ }^{+}\left(\mathrm{B}^{2} \Sigma_{\mathrm{u}}{ }^{+}\right)$and $\mathrm{N}_{2}\left(\mathrm{C}^{3} \Pi_{\mathrm{u}}\right)$ can be generated. Moreover, the $\mathrm{N}_{2}{ }^{+}\left(\mathrm{B}^{2} \Sigma_{\mathrm{u}}{ }^{+}\right)$and $\mathrm{N}_{2}\left(\mathrm{C}^{3} \Pi_{\mathrm{u}}\right)$ produced in nitrogen are more than those produced in air. This is also due to the larger discharge current in pure nitrogen, which is discussed in Section 3.1. In addition, there are more nitrogen molecules participating in the reactions in pure nitrogen than in air, which also results in the larger generation of $\mathrm{N}_{2}{ }^{+}\left(\mathrm{B}^{2} \Sigma_{\mathrm{u}}{ }^{+}\right)$and $\mathrm{N}_{2}\left(\mathrm{C}^{3} \Pi_{\mathrm{u}}\right)$.

Figure 12 aims to further investigate the effects of the pulse duration on the evolution process of the emission intensity of SPS of $\mathrm{N}_{2}$ during one single voltage pulse. The exposure time of the ICCD camera during the measurement is set as $5 \mathrm{~ns}$. It can be found that there are two main intensity peaks from the emission of SPS of $\mathrm{N}_{2}$ that can be seen during one voltage pulse, and the stronger one is generated during the rising time of the voltage pulse (in Figure 12a,c) while the weaker one is generated during the falling time of the voltage pulse (in Figure 12b,d). Furthermore, the first intensity peaks under three pulse durations are almost coincident whenever they are in pure nitrogen or in air. This means that changing the pulse duration has no effect on the discharge during the rising time of the voltage pulse. Additionally, the appearance time of the second intensity peaks has a corresponding delay with the increasing pulse duration. 


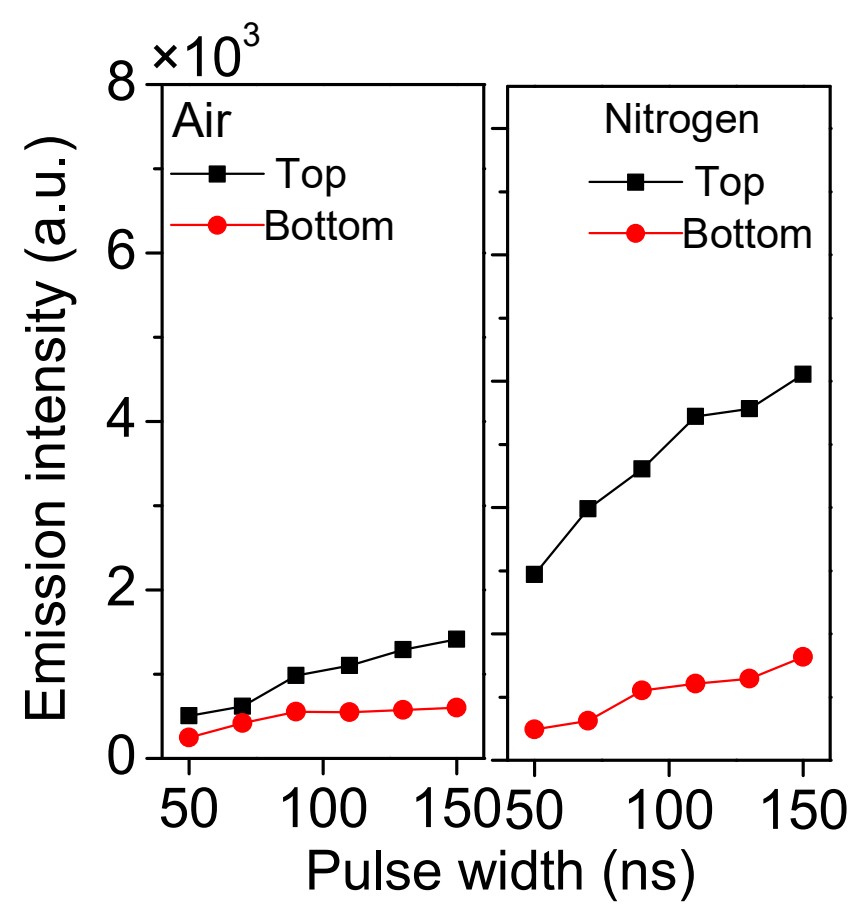

Figure 10. Effects of pulse duration on the emission intensity of FNS of $\mathrm{N}_{2}{ }^{+}$collected from the top and bottom of the reactor under air and nitrogen.

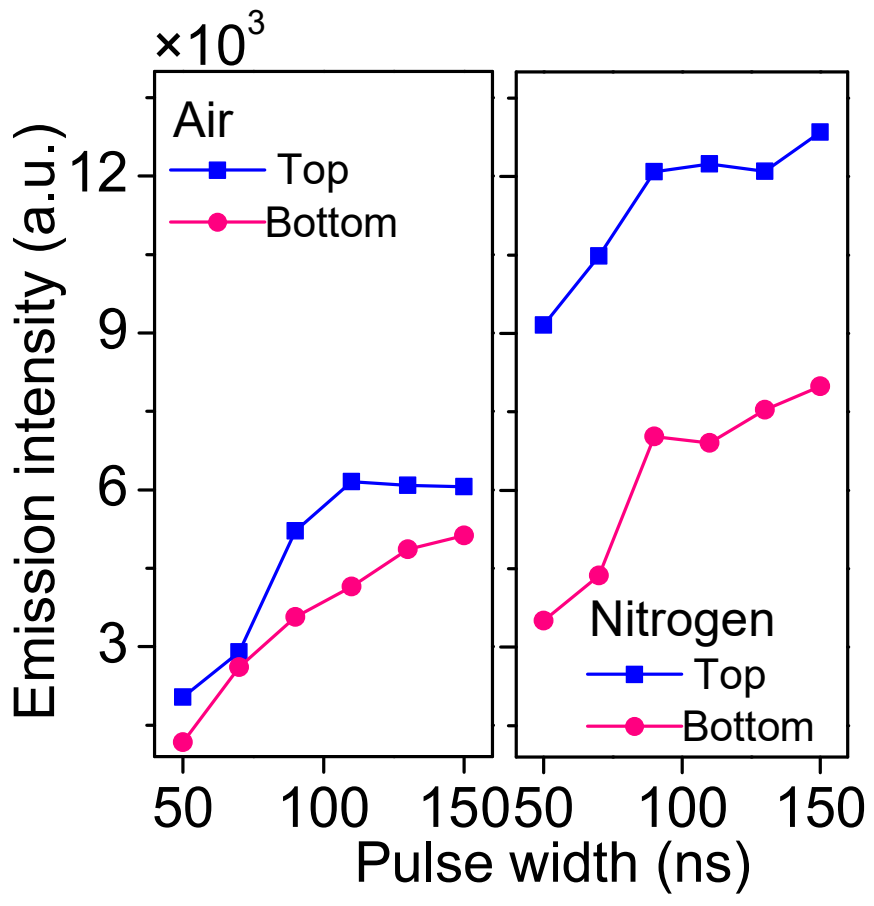

Figure 11. Effects of pulse duration on emission intensity of SPS of $\mathrm{N}_{2}$ collected from the top and bottom of the reactor under air and nitrogen. 

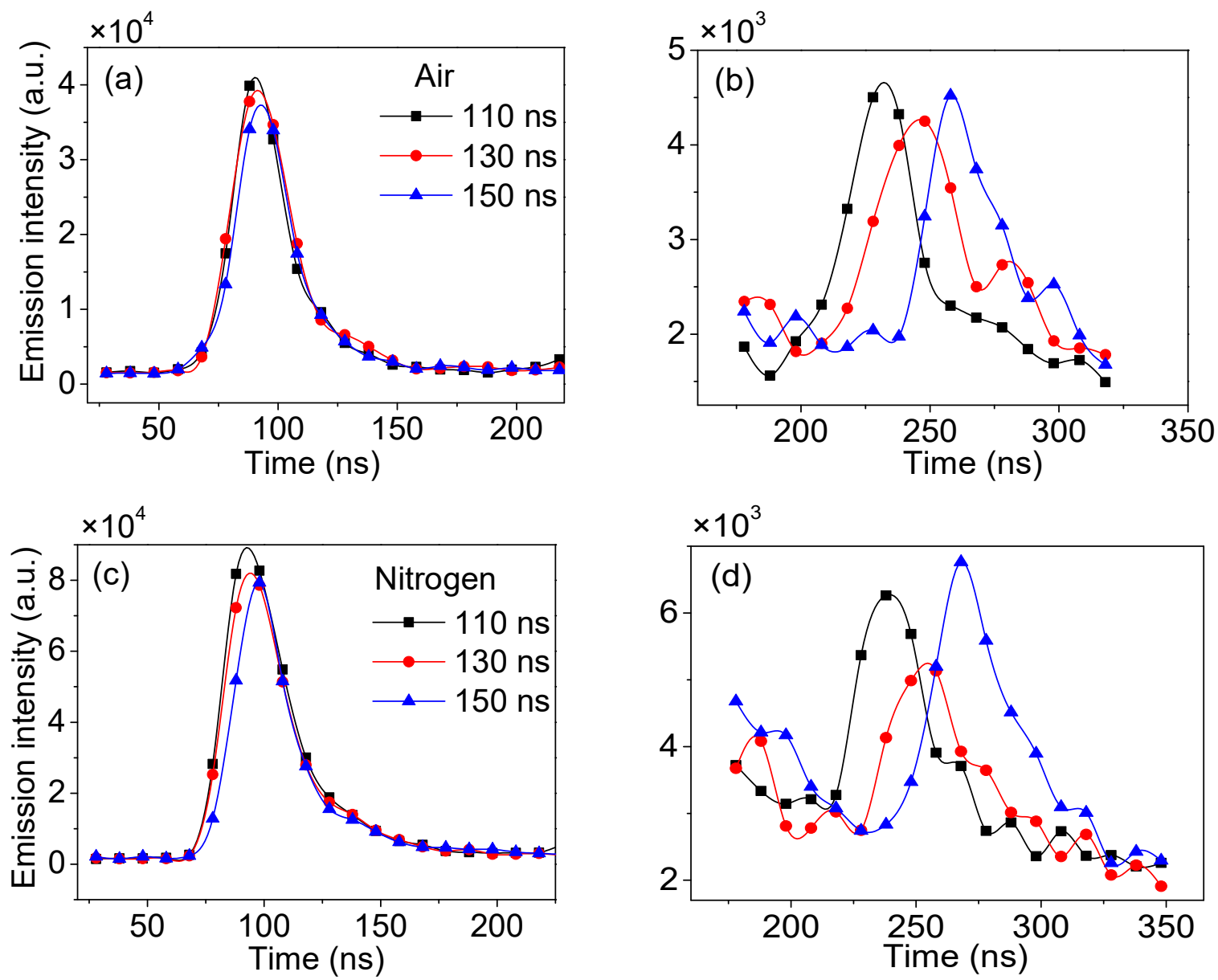

Figure 12. Time evolution of emission intensity of SPS of $\mathrm{N}_{2}$ under (a) air during the rising time of the voltage, (b) air during the falling time of the voltage pulse, (c) pure nitrogen during the rising time of the voltage pulse, and (d) pure nitrogen during the falling time of the voltage pulse with different pulse durations.

\subsection{The Effects of Pulse Rising and Falling Time on Reactive Species}

Figures 13 and 14 show the effects of pulse rising and falling time on the emission intensity of SPS of $\mathrm{N}_{2}$ and FNS of $\mathrm{N}_{2}{ }^{+}$under air and nitrogen. The rising and falling time of the voltage pulse are both set synchronously from $50 \mathrm{~ns}$ to $250 \mathrm{~ns}$. At the top of the reactor in Figure 13, the emission intensity of FNS of $\mathrm{N}_{2}{ }^{+}$decreases when the rising and falling time of the voltage pulse increase from $50 \mathrm{~ns}$ to $150 \mathrm{~ns}$. The reason for this is that the shorter pulse has a higher electron average energy [37], which is beneficial to generate $\mathrm{N}_{2}{ }^{+}\left(\mathrm{B}^{2} \Sigma_{\mathrm{u}}{ }^{+}\right)$. Thus, the emission intensity of FNS of $\mathrm{N}_{2}{ }^{+}$is stronger when the pulse rising and falling time is shorter. In addition, the emission intensity of FNS of $\mathrm{N}_{2}{ }^{+}$increases when increasing the pulse rising and falling time from $150 \mathrm{~ns}$ to $250 \mathrm{~ns}$ in Figure 13b. This means that more discharge channels appear when increasing the rising and falling time of the voltage pulse from $150 \mathrm{~ns}$ to $250 \mathrm{~ns}$. In Figure 14a, the emission intensity of SPS of $\mathrm{N}_{2}$ at the top of the reactor decreases when the rising and falling time of the voltage pulse increase from $50 \mathrm{~ns}$ to $150 \mathrm{~ns}$, and then it increases with increasing the rising and falling time of the voltage pulse further, which shows the same trend with the curve regarding the changes of the emission intensity of FNS of $\mathrm{N}_{2}{ }^{+}$at the top in Figure 13b. In addition, the emission intensity of SPS of $\mathrm{N}_{2}$ at the bottom of the reactor increases first by increasing the rising and falling time of the voltage pulse from $50 \mathrm{~ns}$ to $100 \mathrm{~ns}$, and then it decreases with the rising and falling time of the voltage pulse increase from $100 \mathrm{~ns}$, which has the same trend of the curve regarding the changes of the discharge currents in air shown in Figure 6. These two phenomena mean that the generation of $\mathrm{N}_{2}\left(\mathrm{C}^{3} \Pi_{\mathrm{u}}\right)$ relates to the changes of the discharge channel and electron 
density, which can be reflected by the discharge current and emission spectrum of the FNS of $\mathrm{N}_{2}{ }^{+}$, respectively. In Figure $14 \mathrm{~b}$, the emission intensity of $\mathrm{N}_{2}\left(\mathrm{C}^{3} \Pi_{\mathrm{u}} \rightarrow \mathrm{B}^{3} \Pi_{\mathrm{g}}\right)$ decreases with the increase of the pulse rising and falling time, and this is due to the decrease of the electron average energy with increasing the rising and falling time of the voltage pulse [37].

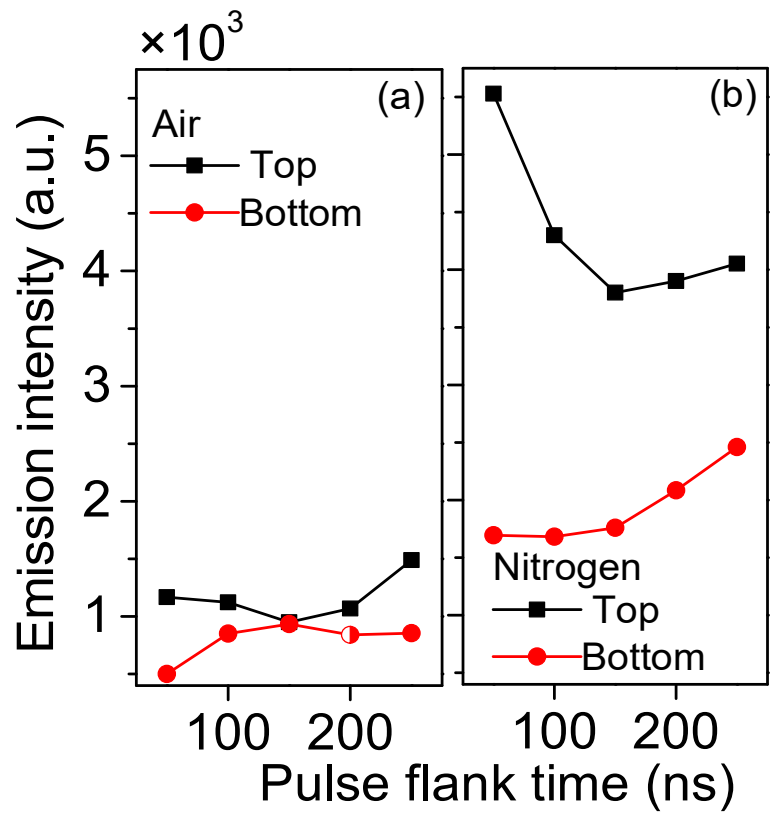

Figure 13. Effects of pulse rising and falling time on the emission intensity of FNS of $\mathrm{N}_{2}^{+}$collected from the top and bottom of the reactor in (a) air and (b) pure nitrogen.

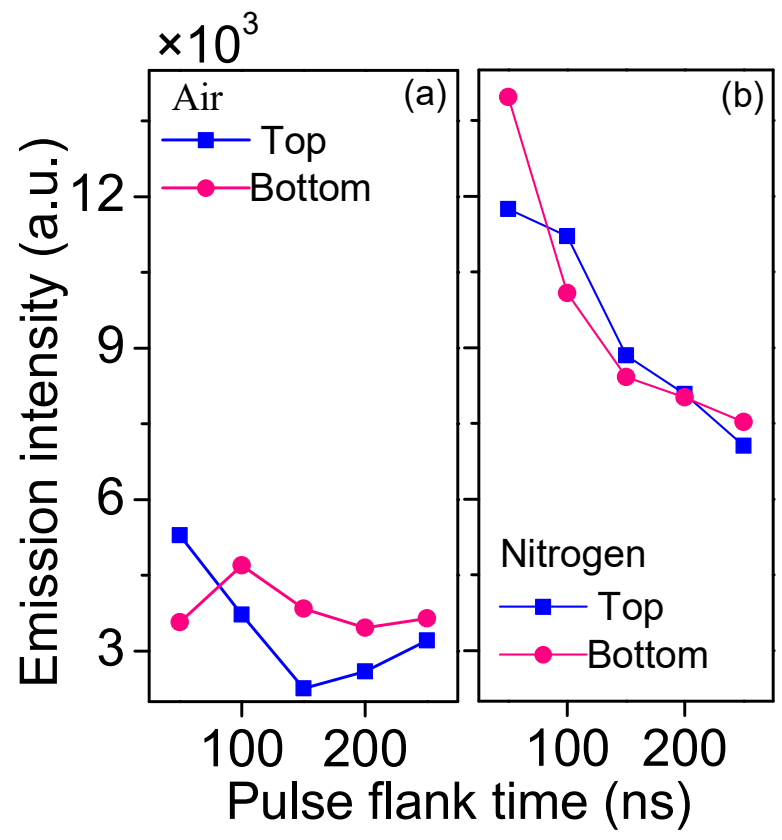

Figure 14. Effects of pulse rising and falling time on emission intensity of SPS of $\mathrm{N}_{2}$ collected from the top and bottom of the reactor in (a) air and (b) nitrogen.

Figure 15 shows the effects of the rising and falling time of the voltage pulse on the time evolution of the emission intensity of the SPS of the nitrogen molecule during one single voltage pulse. Firstly, the intensities decrease with increasing the pulse rising and falling time, which is consistent with the results in Figure 14. Secondly, the moment the peak of the emission intensity of the SPS of $\mathrm{N}_{2}$ appears is delayed with increasing the rising 
and falling time of the voltage pulse, and this is due to the delay of the FP of the discharge current shown in Figure 4. However, the emission intensity of the SPS of $\mathrm{N}_{2}$ during the pulse falling time is too weak to be observed. It can be concluded from Figures 12 and 15 that the duration time of $\mathrm{N}_{2}\left(\mathrm{C}^{3} \Pi_{\mathrm{u}}\right)$ in pure nitrogen is longer than that in air. This is attributed to the longer existence time of the discharge current in nitrogen. In the studies of Ono et al. [38], they found that the existence time of the discharge current decreases with the increase in the oxygen content.

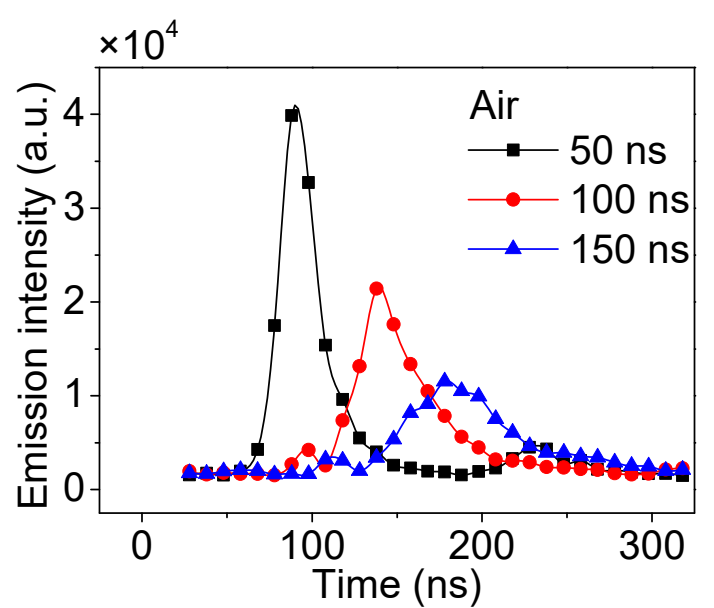

(a)

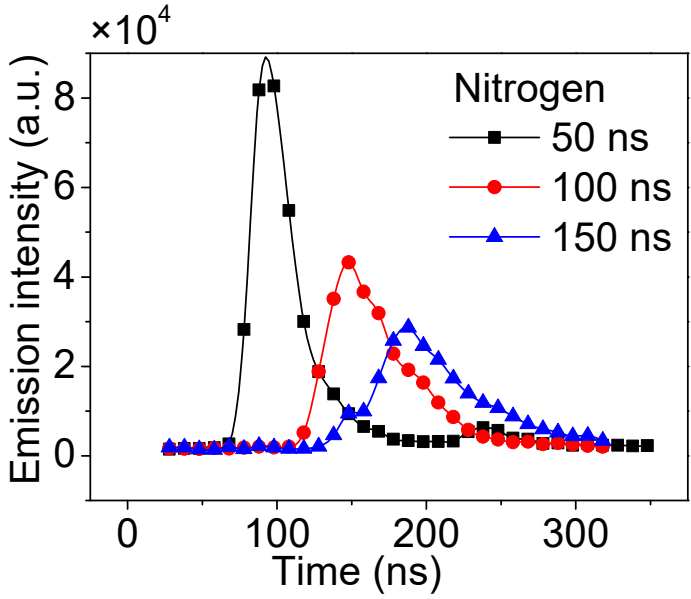

(b)

Figure 15. Time evolution of the emission intensity of SPS of $\mathrm{N}_{2}$ under different pulse rising and falling times in (a) air and (b) pure nitrogen.

\section{Conclusions}

A simplified packed bed dielectric barrier discharge reactor is used to investigate the discharge currents, discharge images, and the reactive species (such as $\mathrm{N}_{2}{ }^{+}\left(\mathrm{B}^{2} \Sigma_{\mathrm{u}}{ }^{+}\right.$) and $\mathrm{N}_{2}$ $\left.\left(\mathrm{C}^{3} \Pi_{\mathrm{u}}\right)\right)$ under different gas compositions, pulse durations, and rising and falling times of the voltage pulse, experimentally. The parameters of voltage pulse have obvious regulations on the discharge currents. The discharge duration and the peak current of the discharge increase with the pulse duration, and the start time of the FP of the discharge current is delayed with increasing the rising time of the voltage pulse. There are bright discharge channels on the top of the reactor, while the discharge on the bottom of the reactor is diffuse, which affects the spatial distributions of $\mathrm{N}_{2}{ }^{+}\left(\mathrm{B}^{2} \Sigma_{\mathrm{u}}{ }^{+}\right)$and $\mathrm{N}_{2}\left(\mathrm{C}^{3} \Pi_{\mathrm{u}}\right)$. The generation of $\mathrm{N}_{2}{ }^{+}\left(\mathrm{B}^{2} \Sigma_{\mathrm{u}}{ }^{+}\right)$has a strong connection with the existence of the streamer channel, and $\mathrm{N}_{2}$ $\left(\mathrm{C}^{3} \Pi_{\mathrm{u}}\right)$ can be produced in the entire discharge area, which can be proven by capturing the light emission from $\mathrm{N}_{2}\left(C^{3} \Pi_{\mathrm{u}} \rightarrow \mathrm{B}^{3} \Pi_{\mathrm{g}}\right)$ from the discharge area. Hence, the trends of $\mathrm{N}_{2}{ }^{+}$ $\left(\mathrm{B}^{2} \Sigma_{\mathrm{u}}{ }^{+}\right)$and $\mathrm{N}_{2}\left(\mathrm{C}^{3} \Pi_{\mathrm{u}}\right)$ with pulse duration and pulse rising and falling time can reflect the changes of streamer channel distributions and discharge current, respectively. The reactor operated under pure nitrogen has a longer discharge duration and larger discharge area and discharge current, and as a result, the existence time of $\mathrm{N}_{2}{ }^{+}\left(\mathrm{B}^{2} \Sigma_{\mathrm{u}}{ }^{+}\right)$and $\mathrm{N}_{2}\left(\mathrm{C}^{3} \Pi_{\mathrm{u}}\right)$ are longer and there are more than those in air. In general, this simple model can reflect the discharge characteristics in a packed bed reactor well, and the gas composition and electric parameters play important roles in regulating the discharge and reactive species in a packed bed reactor, which can maximize the role of plasma in the application process.

Author Contributions: Writing — original draft preparation, Y.L.; Writing—review and editing, L.Q., L.Z., W.W. and D.Y.; Resources, D.Y. All authors have read and agreed to the published version of the manuscript. 
Funding: This research was funded by the National Natural Science Foundation of China (52077026 and 51977023), the Fundamental Research Funds for the Central Universities (DUT21LK31), the Key Laboratory Fund of National Defense Science and Technology (6142605200303), and the Science and Technology Plan Project of the Ninth Division of the Crops (2021JS003).

Conflicts of Interest: The authors declare no conflict of interest.

\section{References}

1. Kogelschatz, U. Dielectric-barrier discharges: Their History, Discharge Physics, and Industrial Applications. Plasma Chem. Plasma Process. 2003, 23, 1-46. [CrossRef]

2. Babaeva, N.Y.; Kushner, M.J. Self-organization of single filaments and diffusive plasmas during a single pulse in dielectric-barrier discharges. Plasma Sources Sci. Technol. 2014, 23, 065047. [CrossRef]

3. Engeling, K.W.; Kruszelnicki, J.; Kushner, M.J.; Foster, J.E. Time-resolved evolution of micro-discharges, surface ionization waves and plasma propagation in a two-dimensional packed bed reactor. Plasma Sources Sci. Technol. 2018, 27, 085002. [CrossRef]

4. Shao, T.; Wang, R.; Zhang, C.; Yan, P. Atmospheric-pressure pulsed discharges and plasmas: Mechanism, characteristics and applications. High Volt. 2018, 3, 14-20. [CrossRef]

5. Chen, H.L.; Lee, H.M.; Chen, S.H.; Chang, M.B. Review of Packed-Bed Plasma Reactor for Ozone Generation and Air Pollution Control. Ind. Eng. Chem. Res. 2008, 47, 2122-2130. [CrossRef]

6. Michielsen, I.; Uytdenhouwen, Y.; Pype, J.; Michielsen, B.; Mertens, J.; Reniers, F.; Meynen, V.; Bogaerts, A. CO 2 dissociation in a packed bed DBD reactor: First steps towards a better understanding of plasma catalysis. Chem. Eng. J. 2017, 326, 477-488. [CrossRef]

7. Van Durme, J.; Dewulf, J.; Leys, C.; Van Langenhove, H. Combining non-thermal plasma with heterogeneous catalysis in waste gas treatment: A review. Appl. Catal. B Environ. 2008, 78, 324-333. [CrossRef]

8. Tang, X.; Wang, J.; Yi, H.; Zhao, S.; Gao, F.; Chu, C. Nitrogen Fixation and NO Conversion using Dielectric Barrier Discharge Reactor: Identification and Evolution of Products. Plasma Chem. Plasma Process. 2018, 38, 485-501. [CrossRef]

9. Patil, B.S.; Cherkasov, N.; Lang, J.; Ibhadon, A.O.; Hessel, V.; Wang, Q. Low temperature plasma-catalytic $\mathrm{NO}_{\mathrm{x}}$ synthesis in a packed DBD reactor: Effect of support materials and supported active metal oxides. Appl. Catal. B Environ. 2016, 194, 123-133. [CrossRef]

10. Zhu, B.; Zhang, L.-Y.; Li, M.; Yan, Y.; Zhang, X.-M.; Zhu, Y.-M. High-performance of plasma-catalysis hybrid system for toluene removal in air using supported Au nanocatalysts. Chem. Eng. J. 2020, 381, 122599. [CrossRef]

11. Zeng, X.; Li, B.; Liu, R.; Li, X.; Zhu, T. Investigation of promotion effect of $\mathrm{Cu}$ doped $\mathrm{MnO}_{2}$ catalysts on ketone-type VOCs degradation in a one-stage plasma-catalysis system. Chem. Eng. J. 2020, 384, 123362. [CrossRef]

12. Qu, M.; Cheng, Z.; Sun, Z.; Chen, D.; Yu, J.; Chen, J. Non-thermal plasma coupled with catalysis for VOCs abatement: A review. Process Saf. Environ. Prot. 2021, 153, 139-158. [CrossRef]

13. Capp, S.C.; Sawtell, D.A.G.; Banks, C.E.; Kelly, P.J.; Abd-Allah, Z. The effect of $\mathrm{TiO}_{2}$ coatings on the formation of ozone and nitrogen oxides in non-thermal atmospheric pressure plasma. J. Environ. Chem. Eng. 2021, 9, 106046. [CrossRef]

14. Zeng, X.; Zhang, Y.; Guo, L.; Gu, W.; Yuan, P.; Wei, L. Ozone generation enhanced by silica catalyst in packed-bed DBD reactor. Plasma Sci. Technol. 2021, 23, 085501. [CrossRef]

15. Uytdenhouwen, Y.; Meynen, V.; Cool, P.; Bogaerts, A. The Potential Use of Core-Shell Structured Spheres in a Packed-Bed DBD Plasma Reactor for $\mathrm{CO}_{2}$ Conversion. Catalysts 2020, 10, 530. [CrossRef]

16. Zhang, S.; Wang, W.-C.; Yang, D.-Z.; Yuan, H.; Zhao, Z.-L.; Sun, H.; Shao, T. Nanosecond pulsed uniform dielectric barrier discharge in atmospheric air: A brief spectroscopic analysis. Spectrochim. Acta Part A Mol. Biomol. 2019, 207, 294-300. [CrossRef] [PubMed]

17. Zhang, S.; Wang, W.C.; Jiang, P.C.; Yang, D.Z.; Jia, L.; Wang, S. Comparison of atmospheric air plasmas excited by high-voltage nanosecond pulsed discharge and sinusoidal alternating current discharge. J. Appl. Phys. 2013, 114, 163301. [CrossRef]

18. Yang, D.; Wang, W.; Jia, L.; Nie, D.; Shi, H. Production of atmospheric pressure diffuse nanosecond pulsed dielectric barrier discharge using the array needles-plate electrode in air. J. Appl. Phys. 2011, 109, 073308. [CrossRef]

19. Maqueo, P.D.G.; Coulombe, S.; Bergthorson, J.M. Energy efficiency of a nanosecond repetitively pulsed discharge for methane reforming. J. Phys. D Appl. Phys. 2019, 52, 274002. [CrossRef]

20. Shao, T.; Long, K.H.; Zhang, C.; Yan, P.; Zhang, S.C.; Pan, R.Z. Experimental study on repetitive unipolar nanosecond-pulse dielectric barrier discharge in air at atmospheric pressure. J. Phys. D Appl. Phys. 2008, 41, 215203. [CrossRef]

21. Yang, D.Z.; Wang, W.C.; Li, S.Z.; Song, Y.; Nie, D.X. A diffusive air plasma in bi-directional nanosecond pulsed dielectric barrier discharge. J. Phys. D Appl. Phys. 2010, 43, 455202. [CrossRef]

22. Zhang, L.; Yang, D.Z.; Wang, W.C.; Liu, Z.J.; Wang, S.; Jiang, P.C.; Zhang, S. Atmospheric air diffuse array-needles dielectric barrier discharge excited by positive, negative, and bipolar nanosecond pulses in large electrode gap. J. Appl. Phys. 2014, $116,113301$. [CrossRef]

23. Li, Z.; Jin, S.; Xian, Y.; Nie, L.; Liu, D.; Lu, X. A non-equal gap distance dielectric barrier discharge: Between a wedge-shaped and a plane-shaped electrode. Plasma Sources Sci. Technol. 2021, 30, 065026. [CrossRef] 
24. Ono, R.; Nakagawa, Y.; Oda, T. Effect of pulse width on the production of radicals and excited species in a pulsed positive corona discharge. J. Phys. D Appl. Phys. 2011, 44, 485201. [CrossRef]

25. Li, Y.; Yang, D.Z.; Qiao, J.J.; Zhang, L.; Wang, W.Z.; Zhao, Z.L.; Zhou, X.F.; Yuan, H.; Wang, W.C. The dynamic evolution and interaction with dielectric material of the discharge in packed bed reactor. Plasma Sources Sci. Technol. 2020, 29, 055004. [CrossRef]

26. Golubovskii, Y.B.; Maiorov, V.A.; Behnke, J.F.; Tepper, J.; Lindmayer, M. Study of the homogeneous glow-like discharge in nitrogen at atmospheric pressure. J. Phys. D Appl. Phys. 2004, 37, 1346-1356. [CrossRef]

27. Pan, J.; Tan, Z.Y.; Wang, X.L.; Sha, C.; Nie, L.L.; Chen, X.X. Effects of pulse parameters on the atmospheric-pressure dielectric barrier discharges driven by the high-voltage pulses in Ar and $\mathrm{N}_{2}$. Plasma Sources Sci. Technol. 2014, 23, 065019. [CrossRef]

28. Namihira, T.; Tsukamoto, S.; Wang, D.; Katsuki, S.; Hackam, R.; Akiyama, H.; Uchida, Y.; Koike, M. Improvement of NOX removal efficiency using short-width pulsed power. IEEE Trans. Plasma Sci. 2000, 28, 434-442. [CrossRef]

29. Marode, E. The mechanism of spark breakdown in air at atmospheric pressure between a positive point and a plane. I. Experimental: Nature of the streamer track. J. Appl. Phys. 1975, 46, 2005-2015. [CrossRef]

30. Sigmond, R.S. The residual streamer channel: Return strokes and secondary streamers. J. Appl. Phys. 1984, 56, 1355-1370. [CrossRef]

31. Zhang, Y.-T.; Wang, Y.-H. Modeling study on the effects of pulse rise rate in atmospheric pulsed discharges. Phys. Plasmas 2018, 25, 023509. [CrossRef]

32. Wang, Y.; Han, X.; Feng, Y.; Zhang, J.; Wang, D. On the Discharge Mode of Pulsed DBD in Nitrogen at Atmospheric Pressure. IEEE Trans. Plasma Sci. 2016, 44, 2796-2802. [CrossRef]

33. Van Laer, K.; Bogaerts, A. Fluid modelling of a packed bed dielectric barrier discharge plasma reactor. Plasma Sources Sci. Technol. 2016, 25, 015002. [CrossRef]

34. Kim, H.; Teramoto, Y.; Ogata, A. Time-resolved imaging of positive pulsed corona-induced surface streamers on $\mathrm{TiO}_{2}$ and $\gamma$ - $\mathrm{Al}_{2} \mathrm{O}_{3}$-supported Ag catalysts. J. Phys. D Appl. Phys. 2016, 49, 415204. [CrossRef]

35. Li, Y.; Yang, D.-Z.; Qiao, J.-J.; Zhang, L.; Zhou, X.-F.; Zhao, Z.-L.; Yuan, H.; Yan, E.-Y.; Wang, W.-C. Discharge modes and characteristics optimization of nanosecond pulsed discharge in packed bed reactor. J. Phys. D Appl. Phys. 2021, 54, 245206. [CrossRef]

36. Hoder, T.; Höft, H.; Kettlitz, M.; Weltmann, K.-D.; Brandenburg, R. Barrier discharges driven by sub-microsecond pulses at atmospheric pressure: Breakdown manipulation by pulse width. Phys. Plasmas 2012, 19, 070701. [CrossRef]

37. Iza, F.; Walsh, J.L.; Kong, M.G. From Submicrosecond- to Nanosecond-Pulsed Atmospheric-Pressure Plasmas. IEEE Trans. Plasma Sci. 2009, 37, 1289-1296. [CrossRef]

38. Ono, R.; Oda, T. Formation and structure of primary and secondary streamers in positive pulsed corona discharge-Effect of oxygen concentration and applied voltage. J. Phys. D Appl. Phys. 2003, 36, 1952-1958. [CrossRef] 